\title{
Persisting vitamin D deficiency in the Asian adolescent
}

\author{
A E O'HARE, W S UTTLEY, N R BELTON, A WESTWOOD, S D LEVIN, AND F ANDERSON \\ Department of Child Life and Health, University of Edinburgh, Royal Hospital for Sick Children, Edinburgh \\ and Lothian Community Child Health Services
}

SUMmARY A study of 221 children admitted to hospital in the course of a year allowed establishment of a reference range for plasma 25-hydroxyvitamin D. None of these children had evidence of biochemical rickets. Most Asian children, however, were vitamin D deficient in comparison, and this deficiency was most noticeable in girls aged 13 to 15 years: biochemical rickets occurred in six per cent of these adolescent Asians. If vitamin D requirements are not met during the physiological growth spurt, permanent pelvic deformity may result. Vitamin D deficiency persisting into pregnancy will adversely affect the infant, producing an increased risk of hypocalcaemic fits, dental enamel hypoplasia, infantile rickets, and reduced postnatal growth. Our data support the need for vitamin D supplementation, and we suggest that annual oral vitamin $\mathrm{D}$ supplements in the autumn would alleviate the problem.

In 1980 the Department of Health and Social Security working party on the fortification of food with vitamin D concluded that adolescent Asians in Britain remained at risk of developing rickets. ${ }^{1}$ Consideration of vitamin D supplementation was one of the recommendations made to prevent the problem. The presentation of an Asian girl with rickets two years after this publication prompted us to examine the vitamin D status of our local Asian children who had not received vitamin D supplements. A control hospital group had previously been studied to establish a reference range for plasma 25-hydroxyvitamin $\mathrm{D}$ throughout the year. Appropriate studies were performed on both groups to assess the incidence of biochemical rickets.

\section{Subjects}

Asian group. Asian children in the Edinburgh area were identified by school medical officers from class rolls expected to contain 5,11 , and 14 year olds. After initial discussion with the Asian community liaison officer, parents were written to with an explanation of the aims of the survey.

A total of 159 children were identified and although the initial response rate was $70 \%, 66$ children $(41.5 \%)$ were finally sampled. For 9 of the others the home address was not available, for 45 there was no parental response to letters, 18 refused sampling, and 21 who received sampling appointments defaulted.

Arrangements were made with the Asian community liaison officer for out of school sampling. Parents asked for 41 siblings to be sampled at the same time. Hence 107 children with a mean age of 10 years were sampled in May and June 1982. There were 45 boys and 62 girls. Eighty seven per cent of the children had been born in the United Kingdom. All but 7 of the children had parents born outside the United Kingdom. Altogether $71 \%$ of the children were Islamic, $22 \%$ were Sikh, and $7 \%$ were Hindu. Fifty nine per cent of the families gave their country of origin as Pakistan, 30\% India, 5\% Bangladesh, 3\% Nepal, and 3\% Britain.

Control group. This group comprised 221 children admitted to a general medical ward at the Royal Hospital for Sick Children, Edinburgh. All required a venepuncture relating to their admission, and blood samples were taken on admission over a full year. Children taking anticonvulsants or vitamin preparations, or with medical problems thought to alter their biochemical status with regard to calcium metabolism were excluded from the study. Children with abnormal liver function shown by raised plasma $\gamma$ glutamyltransferase concentrations were also excluded. 


\section{Methods}

Plasma calcium, phosphate, alkaline phosphatase and 25-hydroxyvitamin D concentrations were measured in both groups. Calcium was determined by atomic absorption flame photometry; phosphate using a centrifugal analyser by a colorimetric method involving the formation of reduced phosphomolybate; alkaline phosphatase using a centrifugal analyser by a kinetic colorimetric method with 4 nitophenyl-phosphate as substrate and diethanolamine as buffer at $37^{\circ} \mathrm{C} ;{ }^{2}$ and 25 -hydroxyvitamin $\mathrm{D}$ by competitive protein binding assay based on the method of Preece. ${ }^{3}$ The mean interassay coefficient of variation for 25 hydroxyvitamin $\mathrm{D}$ was $10 \cdot 2 \%$.

\section{Results}

Control group. Results were analysed in two age groups because of changes in some parameters with age (Table 1) and because there were no Asian children under 2 years old.

Plasma calcium and phosphate concentrations Children aged over 2 years had significantly higher plasma calcium concentrations than those under 2 years $(\mathrm{P}>0.001)$. Plasma phosphate was significantly higher in the under 2 year olds $(P>0.001)$, and in this group there was a negative correlation with age $(P>0.001)$. This relation could not be shown in the over 2 year olds.

\section{Plasma alkaline phosphatase concentrations}

Fig. 1 shows the relation between alkaline phosphatase and age. The reference ranges (5th to 95th centile) were 287 to $834 \mathrm{U} / \mathrm{l}$ for the under 2 year olds and 285 to $761 \mathrm{U} / 1$ for the over 2 year olds. No child showed evidence of biochemical rickets, defined as the combined features of a low plasma calcium concentration and a high plasma alkaline phosphatase concentration. Six children of various ages had plasma alkaline phosphatase values over $900 \mathrm{U} / \mathrm{l}$ but

Table 1 Plasma calcium and phosphate concentrations in the control group

\begin{tabular}{lll}
\hline & Aged $<2$ years & Age $>2$ years \\
\hline Mean age & 10 months & 6 years 9 months \\
No & 98 & 123 \\
Boys:girls & $73: 25$ & $64: 59$ \\
Calcium (mmol/l) & 2.48 & $2 \cdot 40$ \\
$\quad \begin{array}{l}\text { Mean } \\
\text { Reference range* }\end{array}$ & $2.26-2.69$ & $2 \cdot 18-2.63$ \\
Phosphate (mmol/l) & 1.76 & 1.41 \\
$\quad$ Mean & $0 \cdot 87-2.61$ & $0.83-1.89$ \\
\hline Reference range* & & \\
\hline
\end{tabular}

*The 5th to 95th centiles.

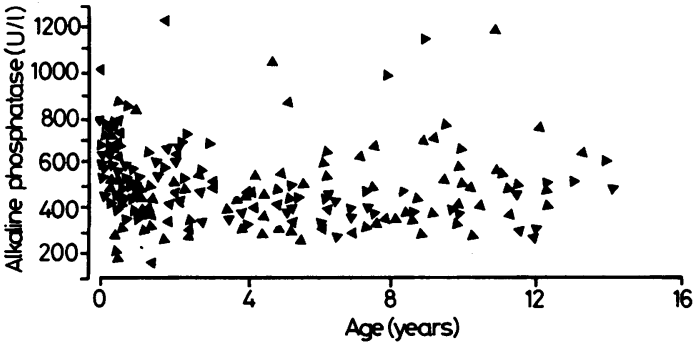

Fig. 1 Plasma alkaline phosphatase concentrations related to age in the control group.

no other evidence of biochemical rickets. (The lowest plasma calcium concentration for these six children was $2.3(\mu \mathrm{mol} / \mathrm{l})$ and the lowest 25 hydroxyvitamin D concentration was $12.23 \mathrm{nmol} / \mathrm{l}$.)

Plasma 25-hydroxyvitamin $D$ concentrations A seasonal variation was found (Fig. 2). The plasma 25-hydroxyvitamin D concentration for the whole group over the year was mean (SD), 44.9 (24.9) $\mathrm{nmol} / \mathrm{l}$. Values for May and June were mean (SD), $60 \cdot 1(19.9) \mathrm{nmol} / \mathrm{l}$ and the lowest concentration in any individual child between the months of May and September was $22.9 \mathrm{nmol} / \mathrm{l}$.

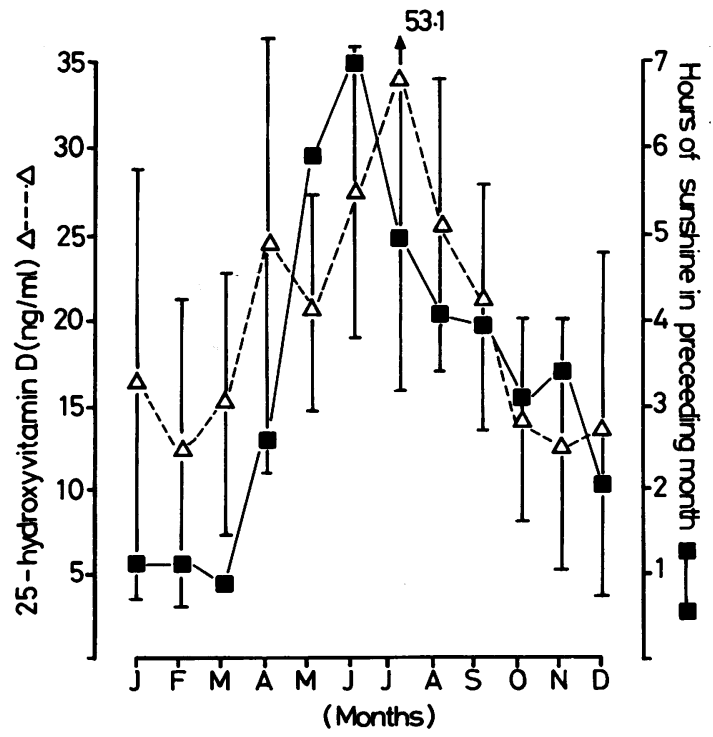

Fig. 2 Seasonal variation of 25-hydroxyvitamin $D$ concentrations in relation to hours of sunshine in the preceding month in the control group. (Vertical bars indicate monthly $S D$ for 25-hydroxyvitamin $D$ ).

Conversion-traditional units to SI: 25 -hydroxyvitamin D $1 \mathrm{ng} / \mathrm{ml} \approx 2.5 \mathrm{nmol} / \mathrm{l}$. 
Table 2 Plasma calcium and phosphate concentrations in the Asian group

\begin{tabular}{ll}
\hline Mean age (years) & 10 \\
No & 107 \\
Boys:girls & $45: 62$ \\
Calcium (mmol/l) & $2 \cdot 36$ \\
$\quad$ Mean & $2 \cdot 12-2 \cdot 56$ \\
Reference range* & \\
Phosphate (mmol/l) & $1 \cdot 57$ \\
Mean & $1 \cdot 2(1-1.94$ \\
Reference range* & \\
\hline
\end{tabular}

*The 5th-95th centiles.

Asian group. The results from the Asian group are shown in Table 2.

\section{Plasma calcium and phosphate concentrations}

There was no significant difference between plasma calcium concentrations in the children aged over 2 years in the control and the Asian groups. The plasma phosphate concentration in the Asian group was, however, significantly above that of the over 2 year old controls $(P>0.001)$. No correlation for age could be shown for either plasma calcium or phosphate concentrations.

\section{Plasma alkaline phosphatase concentrations}

The range of alkaline phosphatase concentrations was 171 to $1660 \mathrm{U} / \mathrm{l}$. There was no correlation between plasma 25-hydroxyvitamin $\mathrm{D}$ and plasma

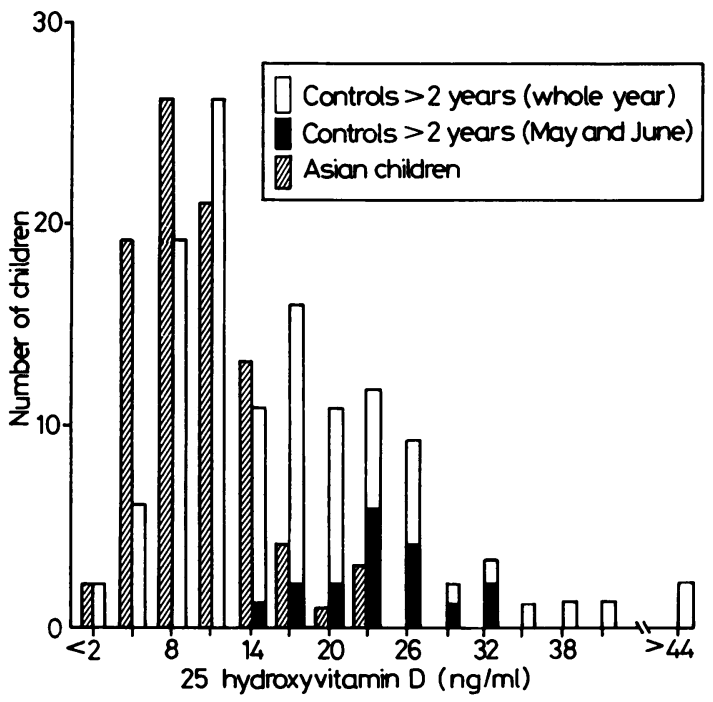

Fig. 3 Comparison of plasma 25-hydroxyvitamin $D$ concentrations in Asian and control groups.

Conversion-traditional units to $.5 /$ : 2.5 -hydroxyvitamin D $1 \mathrm{ng} / \mathrm{ml} \approx 2 \cdot 5 \mathrm{nmol} / \mathrm{l}$.
Table 3 Results in the two Asian girls with biochemical rickets

\begin{tabular}{llllll}
\hline $\begin{array}{l}\text { Case } \\
\text { No }\end{array}$ & $\begin{array}{l}\text { Age } \\
\text { (years) }\end{array}$ & $\begin{array}{l}\text { Calcium } \\
\text { (mmolll) }\end{array}$ & $\begin{array}{l}\text { Phosphate } \\
\text { (mmolll) }\end{array}$ & $\begin{array}{l}\text { Alkaline } \\
\text { phosphatase } \\
\text { (U/l) }\end{array}$ & $\begin{array}{l}\text { 25-hydroxyvitamin D } \\
\text { (nmol/l) }\end{array}$ \\
\hline 1 & 14 & 1.84 & $2 \cdot 03$ & 1208 & $\begin{array}{l}11.4 \\
2\end{array}$ \\
13 & 1.62 & 1.53 & 1660 & $3 \cdot 7$ \\
\hline
\end{tabular}

alkaline phosphatase, calcium, or phosphate concentrations.

\section{Plasma 25-hydroxyvitamin D concentrations}

Plasma 25-hydroxyvitamin D concentrations, assayed in May and June, were mean (SD), 20.7 $(10.7) \mathrm{nmol} / \mathrm{l}$. The vitamin D status of the Asian group was inferior to that of the control group. Fig. 3 shows that this difference is present if comparison is made for control group data for the whole year or for May and June only. The plasma 25hydroxyvitamin $\mathrm{D}$ concentration in Asian boys (mean (SD), $23.7(10.9) \mathrm{nmol} / \mathrm{l})$ was significantly greater than in the girls $(18.7 \quad(9.9) \mathrm{nmol} / \mathrm{l}$ $(P>0.05))$. There was a negative correlation between plasma 25-hydroxyvitamin D and age in the Asian group. The lowest values were found in the older girls aged 13 to 15 years (mean (SD) $18 \cdot 3(9 \cdot 2)$ $\mathrm{nmol} / \mathrm{l}$ ). Two girls had evidence of biochemical rickets (Table 3 ) and one child had radiological evidence of osteomalacia.

\section{Discussion}

This study established a reference range for plasma 25-hydroxyvitamin D concentrations over a full year. No biochemical rickets occurred in the control population despite the finding of some high plasma alkaline phosphatase values. Our data does not suggest that plasma alkaline phosphatase can be used alone as a screening test for rickets in the general population. The Asian children had an inferior vitamin D status with biochemical rickets occurring in six per cent of the 13 to 15 year old girls. This is of concern, particularly as it occurred in a climate of increased awareness of the problem and two years after the publication of recommendations for preventive measures by a government working party.

It is now over 20 years since the original descriptions of rickets and osteomalacia in Asian immigrants in Britain. ${ }^{4}$ Further. reports led to the formation of the government working party. This recognised that the Asian population was at particular risk for the development of rickets during periods of rapid growth in infancy, early childhood 
and puberty, during pregnancy and lactation, and when elderly. It concluded that fortifying foods with vitamin D would lead to some people ingesting unacceptably high amounts of the vitamin, but recommended that health authorities should consider the provision of free vitamin $\mathrm{D}$ supplements to high risk Asian adolescents. Two years after publication subclinical rickets remains a problem in this group against a background of vitamin D deficiency.

Complacency may arise with regard to efforts to prevent rickets in Asians because of an impression that the incidence is becoming less through natural adaptation. In 1972 vitamin D deficiency occurred in $24 \%$ of the Asian population in Glasgow, with the most severe cases occurring in adolescents, particularly girls. ${ }^{5}$ In a Rochdale Asian population a noticeable improvement has been seen in the children over the decade 1970 to 1980 but this has not occurred in the adults. ${ }^{6}$ The authors attribute some of this apparent natural adaptation to increased exposure to sunlight, but an intensive health education programme had also been instituted. The vitamin D status of the children remained inferior to that of the non-Asians and the continued vitamin D deficiency in the women of child bearing age showed a continuing need for vigilance.

It is difficult to be certain of the vitamin D status of Asians residing in countries with abundant sunshine. In some studies they would seem to have a normal range of plasma 25 -hydroxyvitamin D concentrations which is significantly above that of Asians resident in Britain. ${ }^{7}$ The women in these studies, however, had lower concentrations reflecting their state of purdah. Rickets is well recognised in malnourished children in these countries ${ }^{8}$ and biochemical rickets has been described in $33 \%$ of pregnant women in Pakistan. ${ }^{9}$

Controversy still surrounds the importance of each contributing factor leading to the development of rickets. Skin synthesis of vitamin D is prejudiced by reduced exposure and pigmentation. ${ }^{10}$ The Asian diet with its paucity of foods containing vitamin D and high phytate content remains implicated. ${ }^{11}$ The dietary factors have been overcome in many infants with the use of fortified infant feeds but this effect is lost by 18 months of age when the infant partakes of the family diet. ${ }^{12}$

If the adolescent Asian girl does not have her vitamin $\mathrm{D}$ deficiency resolved, requirements are not met during the physiological growth spurt, and permanent pelvic deformity may result. ${ }^{13}$ There is a close correlation between maternal and cord blood 25-hydroxyvitamin $\mathrm{D},{ }^{14}{ }^{15}$ and in states of deficiency the infant may suffer from hypocalcaemic convulsions, ${ }^{15}$ dental enamel defects, ${ }^{15}$ rickets, ${ }^{16}$ and possibly reduced postnatal growth. ${ }^{17}$
Subclinical rickets may be defined as biochemical rickets with low plasma calcium and phosphate and high alkaline phosphatase concentrations; it has been argued that in infants a wrist radiograph has to be included in the assessment. In one series all infants with subclinical rickets had 25-hydroxyvitamin D concentrations below $29.9 \mathrm{nmol} / \mathrm{l}$ and rachitic changes at the wrist. ${ }^{18}$ None had abnormal plasma calcium or phosphate concentrations and the alkaline phosphatase concentration did not correlate with the radiological changes. For the purposes of our study we recalled for radiograph only those Asian children with biochemical abnormalities which were indicative of subclinical rickets, so it is conceivable that the incidence of radiological rachitic changes would have been higher.

It would seem impractical to screen all Asian children for biochemical indicators of rickets. As our results indicate that we are still seeing a large percentage of Asians at risk of developing rickets, all medical and nursing personnel must continue to be aware of the problem. Routine questioning regarding the possibility of bone pain and appropriate skeletal examination should form part of the school medical assessment. Health education directed at vulnerable ethnic groups is still required and should include literature in the appropriate languages. The impact of health education alone remains controversial. The incidence of rickets in Glasgow decreased dramatically (from 12.5 to $4.5 \%$ ) in the five years after the Greater Glasgow Health Board launched its rickets prevention programme ${ }^{19}$ but their programme included the provision of free vitamin D supplements, and in $1979,74 \%$ of their Asian children were taking these. It is argued that the extent to which education can modify the life styles of Asian groups remains limited and perhaps this is even more the case for Asian women.

We conclude with other workers that until there is an improvement in the vitamin D status of the Asian population in Britain, adolescents should receive supplements. This is of particular importance to the adolescent girl who may soon be embarking on child bearing. Ergocalciferol $(2.5 \mathrm{mg})$ given by the oral route in the autumn to produce a sustained rise in plasma 25-hydroxyvitamin D until the springtime would seem appropriate. ${ }^{20}$

We wish to thank Dr P M Ludlam, lately Clinical Coordinator for Child Health Services, Lothian Health Board, for assistance in the project.

\footnotetext{
References

' Department of Health and Social Sccurity. Rickets and osteomalacia. Report on Health and Social Subjects, no 19. London: HMSO, 1980.
} 
2 Deutsche Gesellschaft fur Klinische Chemie. Standard method for the determination of alkaline phosphatase activity. Zeitschrift fur Klinische Chemie und Klinische Biochemie 1972;10:290.

3 Preece MA, O'Riordan JLH, Lawson DEM, Kodicek E. A competitive protcin-binding assay for 25-hydroxycholecalciferol and 25-hydroxyergocalciferol in serum. Clin Chim Acta 1974: 54:235-42.

4 Dunnigan MS, Paton JP, Hasse S, McNicol G, Gardner MD Smith CM. Late rickets and osteomalacia in the Pakistani community in Glasgow. Scott Med J 1962;7:159-67.

5 Ford JA, Colhoun EM, McIntosh WB, Dunnigan MG. Rickets and osteomalacia in the Glasgow Pakistani community, 19611971. Br Med J 1972;ii:677-80.

- Stephens WP, Klimiuk PS, Warrington S, Taylor JL, Berry JL, Mawer EB. Observations on the natural history of vitamin $\mathrm{D}$ deficiency amongst Asian immigrants. $Q \mathrm{~J}$ Med 1982;51:171-88.

${ }^{7}$ Rashid A, Mohammed T, Stephens WP, Warrington S, Berry JL, Mawer EB. Vitamin D status of Asians living in Pakistan. Br Med J 1983;286:182-4.

${ }^{8}$ Raghuramlu N, Reddy V. Serum 25-hydroxy vitamin D levels in malnourished children with rickets. Arch Dis Child 1980;55: 285-7.

9 Rab SM, Bascer A. Occult osteomalacia amongst healthy and pregnant women in Pakistan. Lancet 1976;ii:1211-3.

11 Clemens TL, Henderson SL, Adams JS, Holick MF. Increased skin pigment reduces the capacity of the skin to synthesise vitamin D3. Lancet 1982:i:74-6.

$"$ Robertson I, Kelman A. Dunnigan MS. Chapatti intake, vitamin D status and Asian rickets (letter). Br Med J 1977;i: $229-30$
12 Singleton N, Tucker SM. Vitamin D status of Asian infants. $\mathrm{Br}$ Med J 1978;i:607-10.

13 Ellis G, Woodhead JS. Cooke WT. Serum 25-hydroxy vitamin D concentrations in adolescent boys. Lancet 1977;i:825-8.

14 Belton NR, Elidrissy ATH, Gaafar TH, et al. Maternal vitamin D deficiency in the pathogenesis of rickets in Saudi Arabia. In: Norman AW, Schaefer K. Herrath DV, Grigolcit H-G, eds. Vitamin D chemical biochemical and clinical endocrinology of calcium metabolism. Berlin: de Gruyter, 1982:735-7.

15 Cockburn F, Belton NR, Purvis RJ, et al. Maternal vitamin D intake and mineral metabolism in mothers and their newborn infants. Br Med $J$ 1980;281:11-4.

${ }^{16}$ Ford JA, Davidson DC, McIntosh WB, Fyfe WM, Dunnigan MG. Neonatal rickets in Asian immigrant population. Br Med J 1973;28:211-2.

17 Brooke OG, Butters F, Wood C. Intrauterine vitamin D nutrition and post-natal growth in Asian infants. $\mathrm{Br} \mathrm{Med} \mathrm{J}$ 1981;283:1024.

${ }^{18}$ Pettifor J, Isdale JM, Sahakian J, Banson JDL. Diagnosis of subclinical rickets. Arch Dis Child 1980;55:155-7.

19 Goel KM, Sweet EM, Campbell S, Attenburrow A, Logan RW, Arneil GC. Reduced prevalence of rickets in Asian children in Glasgow. Lancet 1981;ii:405-6.

20) Stephens WP, Klimiuk PS, Berry JL, Mawer EB. Annual high dose vitamin D prophylaxis in Asian immigrants. Lancet 1981 ;ii: 1199-202.

Correspondence to Dr N R Belton, Department of Child Life and Health, 17 Hatton Place, Edinburgh EH9 1UW.

Received 9 April 1984 